\title{
Perspective on the dynamics of cancer
}

\author{
Youcef Derbal(1)
}

\author{
Correspondence: \\ yderbal@ryerson.ca \\ Ted Rogers School of Information \\ Technology Management, Ryerson \\ University, Toronto, Canada
}

\begin{abstract}
Background: The genetic diversity of cancer and the dynamic interactions between heterogeneous tumor cells, the stroma and immune cells present daunting challenges to the development of effective cancer therapies. Although cancer biology is more understood than ever, this has not translated into therapies that overcome drug resistance, cancer recurrence and metastasis. The future development of effective therapies will require more understanding of the dynamics of homeostatic dysregulation that drives cancer growth and progression.

Results: Cancer dynamics are explored using a model involving genes mediating the regulatory interactions between the signaling and metabolic pathways. The exploration is informed by a proposed genetic dysregulation measure of cellular processes. The analysis of the interaction dynamics between cancer cells, cancer associated fibroblasts, and tumor associate macrophages suggests that the mutual dependence of these cells promotes cancer growth and proliferation. In particular, MTOR and AMPK are hypothesized to be concurrently activated in cancer cells by amino acids recycled from the stroma. This leads to a proliferative growth supported by an upregulated glycolysis and a tricarboxylic acid cycle driven by glutamine sourced from the stroma. In other words, while genetic aberrations ignite carcinogenesis and lead to the dysregulation of key cellular processes, it is postulated that the dysregulation of metabolism locks cancer cells in a state of mutual dependence with the tumor microenvironment and deepens the tumor's inflammation and immunosuppressive state which perpetuates as a result the growth and proliferation dynamics of cancer.
\end{abstract}

Conclusions: Cancer therapies should aim for a progressive disruption of the dynamics of interactions between cancer cells and the tumor microenvironment by targeting metabolic dysregulation and inflammation to partially restore tissue homeostasis and turn on the immune cancer kill switch. One potentially effective cancer therapeutic strategy is to induce the reduction of lactate and steer the tumor microenvironment to a state of reduced inflammation so as to enable an effective intervention of the immune system. The translation of this therapeutic approach into treatment regimens would however require more understanding of the adaptive complexity of cancer resulting from the interactions of cancer cells with the tumor microenvironment and the immune system.

Keywords: Cancer dynamics, Tumor microenvironment, Cardinal signaling pathways, Cancer inflammation, Tumor immunosuppression, Dysregulated cellular processes, Cancer associated fibroblasts, Tumor associated macrophages

\section{Biomed Central}

(c) The Author(s). 2017 Open Access This article is distributed under the terms of the Creative Commons Attribution 4.0 International
License (http://creativecommons.org/licenses/by/4.0/), which permits unrestricted use, distribution, and reproduction in any medium,

(c) The Author(s). 2017 Open Access This article is distributed under the terms of the Creative Commons Attribution 4.0 International
License (http://creativecommons.org/licenses/by/4.0/), which permits unrestricted use, distribution, and reproduction in any medium, provided you give appropriate credit to the original author(s) and the source, provide a link to the Creative Commons license, and indicate if changes were made. The Creative Commons Public Domain Dedication waiver (http://creativecommons.org/ publicdomain/zero/1.0/) applies to the data made available in this article, unless otherwise stated. 


\section{Background}

Cancer is a complex disease which continues to challenge old and newly approved therapeutic drugs. The relapse of treated patients and the inevitable drift to metastasis highlight the adaptive complexity of cancer. Although the mechanisms underlying the genesis and progression of cancer are better understood than ever [1], the therapeutic drugs being developed so far did not lead to an inflexion towards a cure for all patients [2]. The collateral damage of chemotherapy and radiation and the inevitable onset of resistance followed by metastasis is a serious limitation of the current cancer armamentarium. The selective targeting of oncogenes through kinase inhibition is promising in its rationale but equally exposed as a therapy to the problem of drug resistance. Combining multiple drugs is an approach that has been explored to overcome resistance, however more research is needed to achieve effective combinations of drugs that are tolerable and non-interactive [3]. Immune checkpoint blockades provide another cancer therapeutic avenue with a clinically proven potential [4-10]. Immunotherapy's impact on patient survival rate and lifespan will ultimately depend on the extent to which an effective antitumor immunity is achieved with manageable immune toxicity [11]. Adoptive cell transfer using engineered T cells that recognize specific cancer antigens has shown promising clinical results against some cancers such as acute lymphoblastic leukemia [12, 13]. However, given cancer heterogeneity, finding target antigens that are unique to cancerous cells is a critical challenge for this type of therapy [14]. On the other hand, oncolytic virotherapy, which has recently received increased attention, faces the formidable challenge of virus delivery and intratumoral spread and cross-priming the host immune system against the cancer while mitigating safety concerns such as virus mutability and unexpected toxicity [15]. Other cancer therapeutic strategies have also been explored, including epigenetic therapy consisting of DNAdemethylation and inhibition of histone deacetylases to undo the effect of mutated chromatin-remodeling enzymes implicated in cancerous cell proliferation [16-18]. These advances in cancer drug development are increasingly leveraged within integrated treatment strategies, combining surgery, radiation, chemotherapy, endocrine therapy, kinase inhibition and immune checkpoint blockades, to extend their therapeutic reach to larger groups of patients and achieve longer remission periods for those patients that are responsive [19]. Although an improvement of the survival rates for some types of cancer have been achieved, a cure is still beyond reach [2]. Indeed, even the simultaneous combination of multiple targeted therapies is predicted to fail in the presence of a single genetic mutation that is resistant to multiple targeted drugs [20]. Drug-conjugated antibodies may not improve cancer free survival either. For example the combination of Bevacizumab and paclitaxel did not deliver any significant benefit for HER2+ breast cancer [3], highlighting the need for more understanding of how to combine antibodies with traditional chemotherapy and targeted tyrosine kinase inhibitors to minimize toxicity and maximize effectiveness. In any case, the evolving genetic heterogeneity of tumors will remain a serious challenge to the development of an effective cancer therapy through the combination of multiple drugs [19, 21]. This complex adaptive nature of cancer, for which even targeted combination therapies would not address unmet therapeutic needs, constitutes a compelling reason to explore a paradigm shift in the search for a cure. It may be argued that cancer adaptive complexity can only be successfully countered by a likewise adaptive therapeutic 
strategy. The development of such therapeutic system requires a comprehensive understanding of the integrated working of the drivers underlying the dynamics of homeostatic dysregulation that drives cancer progression. Significant advances have been made on this front, yielding a chronological map of the processes underlying carcinogenesis and the cellular and tissue dynamics driving cancer progression leading to metastasis [1]. Indeed, the explicit framing of cancer dynamics in terms of hallmarks identifies specific windows of therapeutic interventions that can be used to disrupt the obstinate march of cancer. The challenge however, is how to counter the adaptive complexity of cancer dynamics in response to therapy. The genetic diversity within a tumor and across tumors of the same cancer type is a formidable challenge making of the disease a moving target which limits the staying effectiveness of most cancer drugs. The active role of the tumor microenvironment (TME) in the promotion and maintenance of tumor growth adds another dimension to the complexity of cancer dynamics. This makes it an imperative that the search for effective therapies should take in consideration not only the genetic drivers of the disease but also the confluence of their effects in collusion with the TME to promote cancer progression. In this respect, the article explores an understanding of cancer dynamics from the perspective that information and energy are the primary organizing drivers of the adaptive complexity of living organisms [22]. More specifically, cancer dynamics are postulated to be driven by the reciprocal dependence between the dysregulated flow of information channeled by the genetically altered cell signaling networks and the energy production and biomass transformations enacted by a reprogrammed metabolism. Furthermore, it is assumed that the TME represents a necessary catalytic milieu enabling the provision and exchange of growth factors and nutrients required for tumor growth. A key element of this view of cancer dynamics is the role of feedback as a double edge lever of biological regulation. Indeed, on one hand feedback enables robustness of biological processes and the maintenance of cellular and tissue homeostasis [23-26]. However, beyond a certain degree of signaling and metabolic dysregulation, feedback between the signaling pathways, metabolism and the TME may become the mechanistic conduit for exacerbating the drift away from homeostasis and for driving tumor growth. In this respect, do the feedback signals and biomass exchanges between cancer cells (CCs) and the TME carry cancer vulnerabilities that can be therapeutically targeted? If such vulnerabilities do exist, then how can they be leveraged to turn on the cancer kill switch and enlist a decisive intervention of the immune system? These and other questions related to cancer dynamics will be explored in the following sections using simplified models of cellular processes and the tumor microenvironment.

\section{Genesis of cancer dynamics}

The causal effects linking genetic alterations and the phenotypic state trajectories of cancer cells are enacted within the TME context and channeled through operational deviations from homeostasis of growth, proliferation, autophagy, angiogenesis, apoptosis, survival, focal adhesion, cell cycle, DNA repair, and energy production. The dysregulation of these cellular processes are known to implicate various sets of genetic drivers as supported by genome wide studies of different cancers [27-32]. However, the high number of assumed cancer driver genes poses a challenge to the development of a much needed insight about the dynamics of cell signaling and metabolic interactions 
underlying tissue homeostasis. Furthermore, it is not clear whether all the genes identified by the various genome wide studies have an equally determinant impact on carcinogenesis and cancer progression. Assumptions about the existence of principles driving the overall dynamics of cancer as a system of heterogeneous multiplicity of biological parts and modules, may points to a select high confidence set of cancer implicated genes as the key determinants of carcinogenesis. In this respect, it has been suggested that biological complexity is driven by a reciprocal causality between energy/biomass production and information flow [22]. This notion has been recently supported by a comprehensive analysis of the reciprocal regulation shown to exist between the cell signaling network and the metabolic circuitry [33-35]. Therefore, it may be plausible to hypothesize that the genes mediating the interactions between cell signaling and metabolism are critical determinants of the dynamics underlying tissue homeostasis. These levers of the signaling-metabolic interface include the energy sensor AMPK, the proliferation regulator MTOR, the growth regulators MYC and AKT, the oxygen sensor HIF, and the apoptotic trigger P53 (see Fig. 1). These genes are interconnection hubs of the signaling circuitry that maintains tissue homeostasis

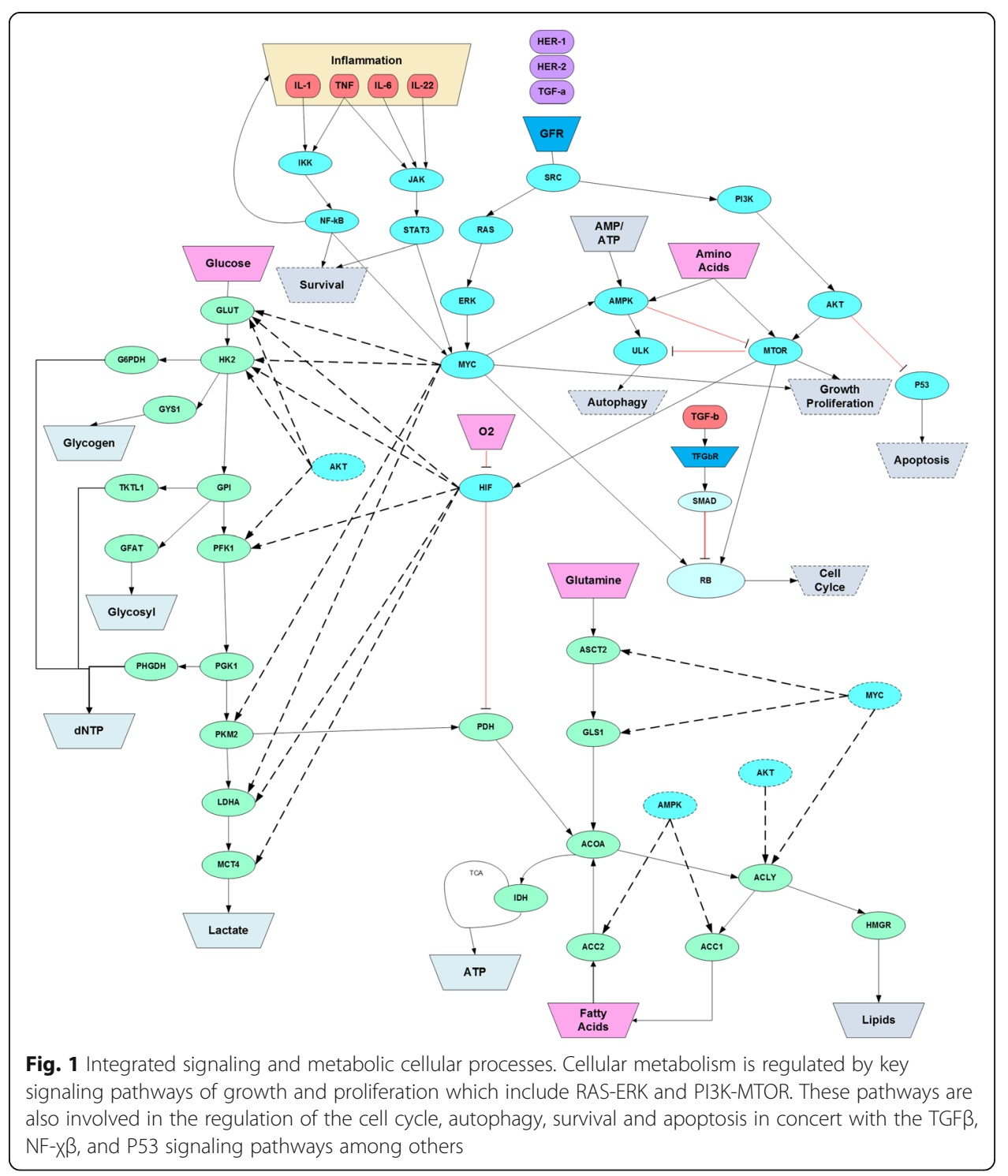


and prevents runaway growth and proliferation. For instance, MYC and AKT, which are the end effectors of mitogenic pathways, regulate the uptake of glucose through GLUT as well as the catalytic capacity of the downstream glycolytic enzymes including LDHA and MCT4. An upregulation of mitogenic pathways, whether caused by mutant genes or overabundance of growth factors, would amplify the glycolytic flux feeding the glycosyl pathway, the PPP (pentose phosphate pathway), the serine pathway, and the one carbon metabolism, which drive biomass production, including nucleotides, glycosyl, glycogen, and non-essential amino acids (AA). Under hypoxic conditions, an elevated glycolytic activity can be further enhanced by HIF through its excitatory action on the lactate transporter MCT4 as well as the inhibition of PDH which limits as a result the flux of pyruvate from glycolysis to the tricarboxylic acid (TCA) cycle. Furthermore, the mutant form of IDH found in many cancers leads to the production of the oncometabolite 2-HG which further drives the action of HIF as a promoter of heightened glycolysis under hypoxic conditions. Taken together, MYC and AKT as the glycolytic effectors of the RAS-ERK and PI3K-AKT pathways, can intensify glycolysis either in response to higher levels of extracellular stimuli such as growth factors and cytokines or as a result of oncogenic alterations involving genes such as RAS, RAF and EGFR. Moreover, tumor growth leads to hypoxic conditions in the region trailing the invasive front, causing HIF to deepen the elevated glycolytic regime as explained above. In addition to its regulatory control on glycolytic rate, MYC can upregulate the uptake of glutamine through ASCT2 and its transformation by GLS1 to feed the TCA cycle as well as modulate the synthesis of lipids, with the help of AKT. In summary, the signaling pathways converging on MYC, AKT and HIF have the capacity to reprogram cell metabolism to fulfill the biomass needs of tumor growth by directing the biosynthesis of proteins, lipids and nucleotides while maintaining an adequate level of cellular ATP. However, in order to sustain tumor growth progression, MTOR needs to be coopted to promote runaway cell proliferation by driving ribosomal protein synthesis and translation. While it is widely accepted that MTOR is inhibited by AMPK under conditions of lower cellular energy sensed by a higher AMP/ATP ratio, it has been recently shown that both AMPK and MTOR can be concurrently activated by amino acids [36]. The effects of concurrent AMPK and MTOR activation would constitute a convergence of the cell regulatory dynamics in support of proliferation by driving mitochondrial biogenesis, ATP generation, fatty acid oxidation, ribosomal protein synthesis, translation, cell cycle progression through the restriction point, and autophagy. The drive towards uncontrolled proliferation is further accentuated in the presence of mutant P53 and PTEN since these are expected to be less effective in dampening the survival signals sourced from AKT. The signaling dynamics integrated through the actions of the effectors MYC, AMPK, AKT, MTOR, HIF, PTEN, and P53 can sustain tumor growth progression provided that extracellular stimuli, such as growth factors and cytokines, are maintained along with sufficient availability of glucose, glutamine, amino acids and fatty acids. In other words, while genetic alterations lead to dysregulated signaling and a reprograming of metabolism in support of cell growth and proliferation, synergetic intercellular interactions and a promoting tumor microenvironment will still be required to sustain tumor growth. Of particular interest is the contributions of CAFs (cancer associated fibroblasts) and TAMs (tumor associated macrophages) in helping cancer cells acquire the necessary supply of glutamine, fatty acids, and amino acids on one hand and at the same time maintaining an inflammatory and immunosuppressive environment that protects tumor growth from the intervention of the immune system. 


\section{Role of the tumor microenvironment}

The active role of the TME in promoting and sustaining tumor growth is increasingly accepted as pivotal to cancer progression [37-43]. In particular, it is believed that TAMs and CAFs affect tumor growth and modulate the intervention of the immune system through synergetic interactions with cancer cells [37-39, 44, 45]. More specifically, cancer cells' secreted cytokines and chemokines, such as TGF- $\beta$, are known to activate CAFs [37, 38]. In return, CAFs provide the TME and cancer cells with recycled nutrients such as glutamine and amino acids, believed to be resulting from autophagy caused by oxidative stress, itself induced by adjacent cancer cells [42, 43]. It has also been reported that CAFs and cancer cells co-reprogram their metabolism whereby the lactate output of CAFs feeds the so-called reverse Warburg effect in cancer cells to drive their aerobic metabolism [46]. Furthermore, cytokines and chemokines, such as CCL2, which are secreted by cancer cells and CAFs are known to be involved in the recruitment of macrophages and the induction of their transformation into TAMs [47-49]. Once recruited to the tumor, both TAMs and CAFs have a direct impact on cancer proliferation and metastasis $[47,50]$. In particular, CAFs, which supply cancer cells with recycled nutrients and growth factors as discussed earlier, also release TGF- $\beta$ and promote as a result the immunosuppressive milieu of the TME [51, 52]. The inflammatory and immunosuppressive state of the tumor microenvironment is further reinforced by TAMs, hence shielding cancer cells from the actions of the adaptive immune system [40, 45]. The reciprocal effects characterizing the interactions between TAMs, CAFs and cancer cells will be explored further using the simplified model of TME illustrated in Fig. 2 [1, 37]. The disruption of the interaction signals and nutrient flows between cancer cells, CAFs and TAMs may constitute an effective therapeutic approach to impede the malignant

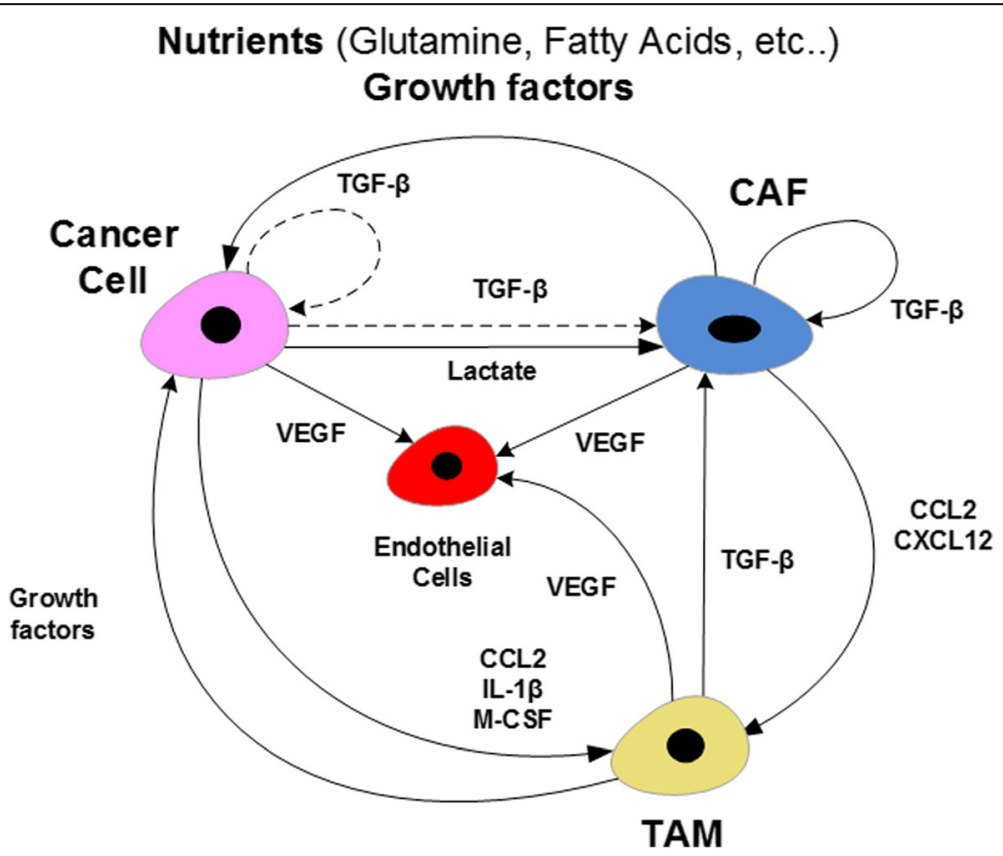

Fig. 2 TME Cells' interactions. The synergetic interactions between CAFs, TAMs and cancer cells promote inflammation, immunosuppression and tumor growth. The dotted lines show indirect interactions, as is the case with the release of TGF- $\beta$ from the extracellular matrix (ECM) degraded by the actions of proteases secreted by cancer cells 
dynamics of the TME and blunt the ability of cancer cells to enlist the support of TAMs and CAFs. Indeed, in addition to the consideration of cancer genetic signatures, cancer therapies should account for the active involvement of the TME in shaping the trajectories of tumor growth dynamics. Therapeutic interventions based on an understanding of these dynamics may lead to desirable clinical outcomes provided that they can shunt the rewiring of the signaling and metabolic networks associated with the accumulation of genetic mutational burden. One step towards the exploration of therapeutic strategies that factor in cancer dynamics would entail understanding how the dysregulated dynamics of the cell signaling and metabolic pathways both impact and reflect the interactions between cancer cells, CAFs and TAMs. Seeking such understanding, a putative model of TME cell interactions, illustrated in Fig. 2, will be used to explore questions about the potential fate of cancer cells under various therapeutic approaches targeting the communication signals and nutrient flows facilitated by the TME. One particular question of interest is: which therapeutic disruption of cancer dynamics would most probably lead to a sustained reversal of tumor growth and keeps at bay the reactionary robustness of the disease state? In other words, is there a kill switch that can be flipped to disable the unholy union between cancer cells, CAFs and TAMs and restore tissue homeostasis?

\section{Modeling cancer dynamics}

Although cancer cell signaling and metabolic dysregulation may be caused by somatic gene mutations, gene copy number variations and DNA hypermethylation, the focus will be primarily on somatic mutations as the main drivers of carcinogenesis. In particular, let $p_{k}, k=1, \ldots, N, \mathrm{~N}>0$, be the probability that the kth gene in a given pathway $w$ harbors deleterious mutations or is subject to copy number variations. The probability $Q_{w}$ that such pathway is dysregulated is then defined as follows:

$$
Q_{w}=1-\prod_{k=1}^{N}\left(1-p_{k}\right)
$$

The value of $p_{k}$ is estimated to be the mutation rate of the gene in question. Using this definition, the probabilities of pathway dysregulation is illustrated for different cancers in Fig. 3 (Additional file 1: Table S1), using the 127 gene set and the classification of cellular processes identified in Kandoth et al. [27]. The likelihood of dysregulation of cellular processes shows a significant dispersion or spread across cancer types as asserted by the corresponding values of the mean and standard deviation of the pathway dysregulation measure (Additional file 1: Table S1). This reiterates the fact that the likelihood of dysregulation for the major cell signaling pathways is dependent on the cancer type. Such variability of the probability of pathway dysregulation as a function of the cancer type also applies to the cell cycle, genome integrity, survival, apoptosis, growth, and proliferation (Additional file 1: Table S1). The "Other" category registers, expectedly, a significant likelihood of dysregulation since it includes genes such as NOCH1, NAV3, MALAT1, and ARHGAP35 known to be associated with cell proliferation as well as other genes such as NPM1 and POLQ which are involved in maintaining genome integrity. While being reductionist compared to the results yielded by the many comprehensive genome wide studies of cancer [27, 28, 30,31, 53], the proposed measure of pathway dysregulation can be instrumental in the analysis of the interactions between cancer cells and the tumor microenvironment (see Fig.4). Of particular 


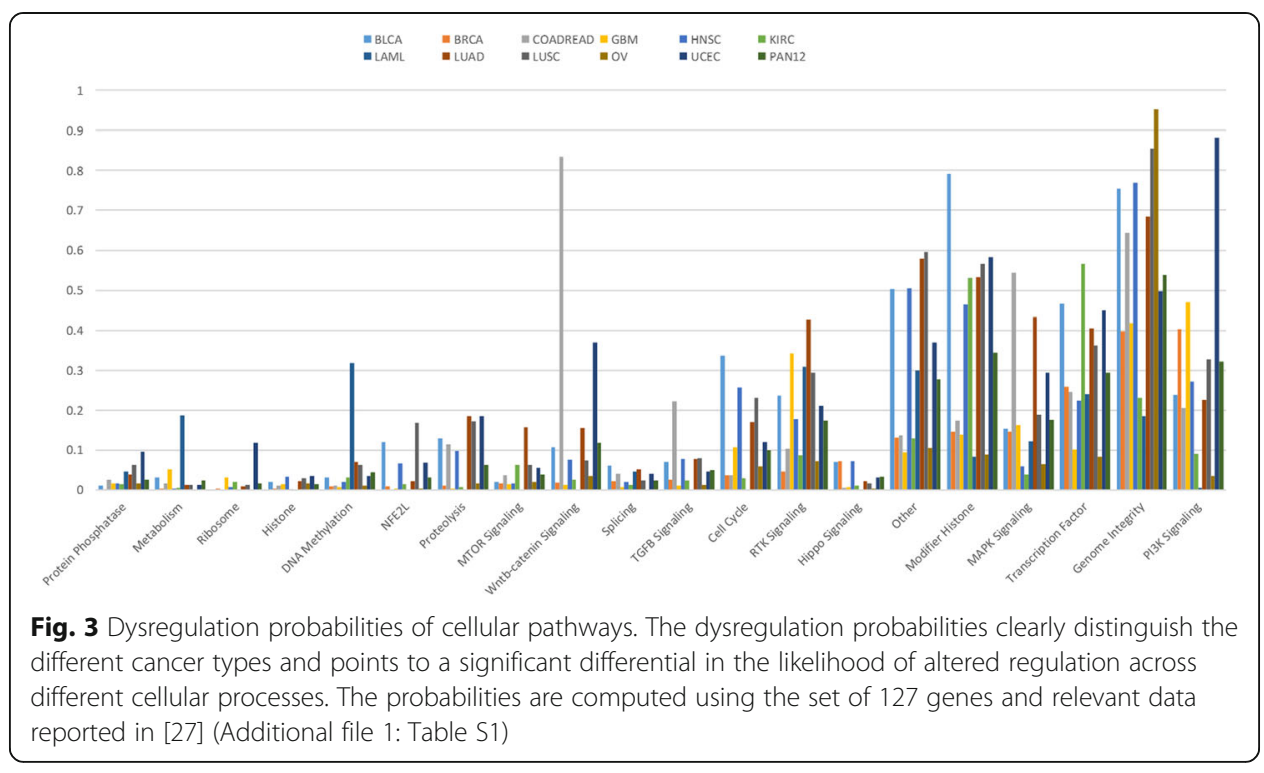

interest is how the effects of these interactions collude with pathway dysregulations to stimulate the dynamics of cancer growth. A number of hypotheses can be put forth about the potential causal chains linking the dysregulation of signaling and metabolic pathways and the initiation and maintenance of cancer growth. First, the probabilities of dysregulation of the RTK, PI3K and MAPK signaling pathways are significantly high

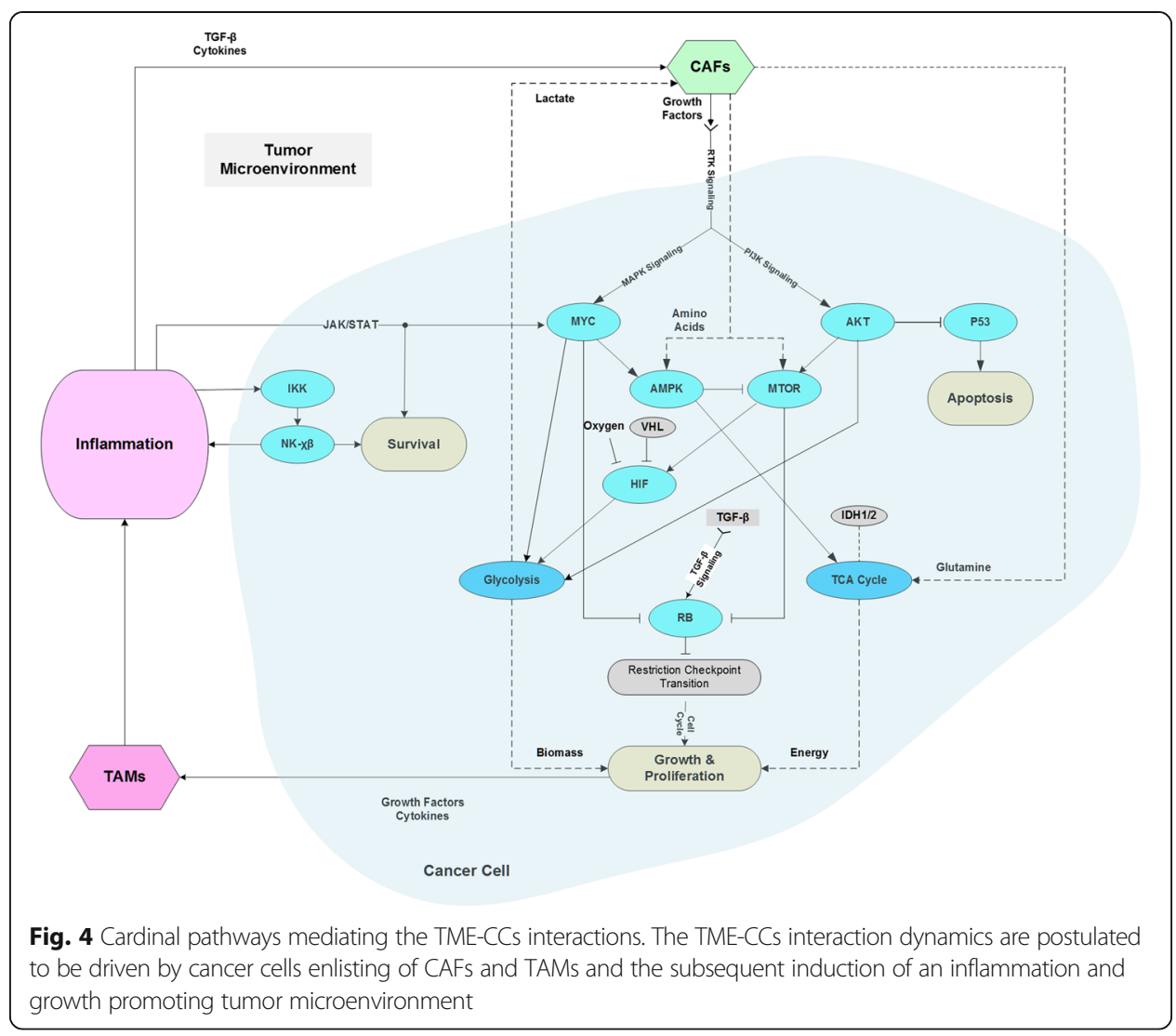


for most types of cancer. Driven by growth factors from the stroma, these pathways may, with high probability, be the first drivers of an upregulated glycolysis in cancer cells. The consequent increase of lactate secretion into the TME will thereafter lead to its acidification and the activation of TGF- $\beta$ [54], leading to the recruitment and transformation of CAFs. In addition to taking up lactate to feed their metabolism, CAFs are thought to undergo autophagy due to oxidative stress induced by cancer cells [37], supplying as a result recycled nutrients such as glutamine and amino acids to neighboring cancer cells. Given the recently reported evidence that AMPK and MTOR can indeed be concurrently activated by amino acids [36], we postulate that it is precisely this additional feedback action of amino acids' provision by CAFs that stabilizes the initiation of cancer cell growth and proliferation. With the concurrent activation of AMPK and MTOR in cancer cells, the ribosomal protein synthesis and translation processes are activated along with an operational TCA cycle, putatively fed by beta oxidation of fatty acids and recycled glutamine from CAFs. In addition, AKT being the end-effector of the PI3K signaling pathway would facilitate lipid synthesis through its action on ACLY. The CCs-CAFs interactions lead to a dependence between cancer cells and the stroma, whereby cancer cells provide lactate and induce the activation of TGF- $\beta$ while CAFs provide glutamine, amino acids, fatty acids and growth factors to feed cancer growth. The dynamics of this CCs-CAFs system are further stabilized and perpetuated by inflammation as well as a ratcheted up release and activation of TGF- $\beta$ in the TME. Furthermore, the oncogenic dysregulation of the RAS, MYC and the MAPK pathways in cancer cells are known to induce the production of growth factors and cytokines such as VEGF, IL-6, IL-10, and IL-1 $\beta$, leading to the recruitment and the tumorigenic transformation of macrophages $[44,55,56]$. The maintenance of an inflammatory TME is further stabilized through the JAK/STAT and the IKK/NF- $\chi \beta$ pathways, whose effects are robustly sustained by a feedback from cancer cells through the production of inflammatory cytokines such as IL-1 $\beta$, IL-6 and TNF- $\alpha$ [57-61]. Not only does inflammation feed the accelerated growth and proliferation through the JAK/STAT pathway, it also drives survival through the IKK/NF- $\chi \beta$ pathway (see Fig. 4).

The stability of the CCs-TME dynamics, as described above, deepens the state of inflammation in the TME, whereby cancer growth and proliferation increases the release and activation of TGF- $\beta$ as well as the secretion of inflammatory cytokines and growth factors maintaining as a result the active roles of the CAFs and TAMs in supporting a cancer promoting TME. The ensuing tumor growth progression is known to be correlated with an increased release and activation of TGF- $\beta$ in the TME as well as a switch of its role from being a tumor suppressor to a tumor promoter [62-67]. This role switching has been hypothesized to be the result of the balance between the dual, antagonistic effects of TGF- $\beta$ on cell proliferation induced through its SMAD-dependent and non-SMAD-dependent signaling pathways $[63,64]$. In line with this hypothesis, the effects of TGF- $\beta$ abundance in the TME, channeled through the MAPK and PI3K signaling pathways (see Fig. 4), would further promote the cancer proliferation dynamics driven by the CCs-CAFs-TAMs interactions. At the same time the TGF- $\beta$ regulation, via its canonical pathway, of the cell cycle passage through the restriction point may be abrogated due to the dysfunction of the RB tumor suppressor (see Fig. 4). These cancer proliferation dynamics are expected to persist given the genetically altered apoptotic and DNA repair pathways, and the immunosuppressive state of the 
TME promoted by the actions of the TGF- $\beta$ both as an inducer of Tregs and as an antagonist of the immune functions of NK, DC and T cells [68-70]. Moreover, recently published results have provided new evidence about the role of TGF- $\beta$, acting cooperatively with VEGF, in maintaining an immunotolerant TME [71].

\section{The stochastic dynamics of cancer}

The core circuitry driving cancer cell state dynamics is suggested to be dynamically wired to balance the production and use of energy and biomass, supporting the imperative of survival and growth. Glycolysis and the TCA cycle represent the two critical cellular processes responsible for carrying out this imperative. Both processes are regulated by competing signals sourced from growth factor stimuli and channeled through the MAPK and PI3K pathways. The balancing act maintaining energy sufficiency and supporting the growth imperative is brokerage by the AMPK antagonistic action on MTOR, while the availability of energy antagonizes AMPK. It is however plausible, as discussed earlier, that the dysregulation of the RTK, MAPK and PI3K pathways can be locked into a pattern of convergent effects that drive the emergence of a stable CCsCAFs interaction dynamics. This CCs-CAFs system is suggested to be the source of an AA-dependent concurrent activation of AMPK and MTOR and the subsequent loss of the regulated balance between the activity levels of glycolysis and the TCA cycle. The causal chain implicating genetic mutations in the altered information flow sourced from growth factor stimuli and leading to the loss of energy-biomass homeostasis, may be characterized using the likelihood measure of pathway dysregulation, introduced earlier. In particular, let $Q_{G l y}, Q_{T C A}, Q_{A P O}, Q_{S R V}$ and $Q_{C C P}$ be the probabilities of dysregulation of glycolysis, the TCA cycle, apoptosis, survival and the cell cycle progression through the restriction point respectively. Given the model of Fig. 4, the dysregulation probabilities are estimated as follows:

$$
\begin{aligned}
& Q_{G l y}=1-Q_{S} *\left(1-p_{M T O R}\right) *\left(1-p_{H I F}\right) *\left(1-Q_{P I 3 K}\right) \\
& Q_{T C A}=1-Q_{S} *\left(1-p_{A M P K}\right) *\left(1-Q_{\text {Metabolism }}\right) \\
& Q_{A P O}=Q_{G I} \\
& Q_{S R V}=1-\left(1-p_{I K K}\right) *\left(1-p_{F O X}\right) *\left(1-Q_{O \text { ther }}\right) *\left(1-Q_{T F}\right) \\
& Q_{C C P}=1-Q_{S} *\left(1-p_{M T O R}\right) *\left(1-Q_{T G F \beta}\right) *\left(1-Q_{\text {Cell Cycle }}\right) *\left(1-Q_{\text {PI3K }}\right) \\
& Q_{S}=\left(1-Q_{R T K}\right) *\left(1-Q_{M A P K}\right) *\left(1-p_{M Y C}\right)
\end{aligned}
$$

$p_{H I F}$ is set to the mutation rate of VHL whose lifted inhibition of HIF leads to the decoupling between glycolysis and the TCA cycle even in the presence of oxygen. Likewise, $p_{A M P K}$ is set to the cumulative rate of mutation and deletions of LKB1, which activates AMPK in response to ATP depletion relative to AMP and ADP. On the other hand $p_{M Y C}$ is estimated using the cumulative rate of mutation and amplification for the members of the MYC family, in particular MYC, MYCL1 and MYCN (Additional file 1: Table S2). Q Q Metabolism, $Q_{G I}, Q_{T F}, Q_{O t h e r}$ are the dysregulation probabilities for the cellular pathways classified in [27] as "Metabolism", "Genome Integrity", "Transcription Factors/Regulators" and "Other" respectively. The latter two sets of genes are deemed to be involved either directly or indirectly in the survival pathways along with IKK and 
the FOX family of genes. The dysregulation probabilities for the five cellular processes (glycolysis, TCA cycle, survival, apoptosis, and cell cycle progression through the restriction point) may constitute a functional signature of the genetic alterations underlying carcinogenesis and tumor growth progression (see Fig. 5, Additional file 1: Table S3). Exploring how the interactions between these key cellular processes lead to the emergence of cancer dynamics may lead to insights about potential vulnerabilities that can be therapeutically targetable. Starting from the assumption that the cell genetic alterations are induced by randomly occurring events, cancer may be viewed as a dynamical system driven by the stochastic states of the cellular processes. Each cellular process $w$ can either be in a state of dysregulation with a probability $Q_{w}$, as computed above, or in a regulated state with a probability $1-Q_{w}$. Let the outputs of glycolysis and the TCA cycle be $f(v(t), \vartheta)$ and $g(v(t), \varphi)$ representing the residual energy and cell biomass that can be used for growth, where $\vartheta$ and $\varphi$ are random variables representing the states of glycolysis and the TCA cycle respectively. $v(t)$ is a vector representing the availability of nutrients, growth factors, and cytokines. The convolution of these stochastic processes defined as $h(t)=\int_{0}^{t}$ $f(\tau, \vartheta) g(t-\tau, \phi) d \tau$, where $\mathrm{t}$ and $\tau$ are time variables, is postulated to represent the cancer initiating signal. In other words, tumorigenic growth is driven by the stochastic convergence of dysregulated TCA and glycolysis processes which leads to the concurrent availability of sufficient energy and biomass to feed a runaway cancer growth and proliferation. The growth signal $h(t)$ is subject to the control of the TGF $\beta$ pathway which regulates the cell cycle passage through the restriction checkpoint. The regulatory action of the TGF $\beta$ pathway is also represented by a stochastic signal $r(v(t), \zeta)$, where $\zeta$ is the pathway's stochastic state. Similarly, the survival and apoptotic signals can also be modeled by stochastic processes denoted as $w(v(t), \phi)$ and $u(v(t), \xi)$, where $\phi$ and $\xi$ represent the stochastic states of dysregulation associated with the survival and apoptotic pathways respectively (see Fig. 6). This perspective on cancer dynamics places genetic alterations as the initiators of cancer growth through the reprogramming of metabolism and considers this last to be the trigger of the feedback dynamics between cancer cells and the TME. These dynamics will ultimately lead to the removal of the restriction on the cell cycle progression, the amplification of the inflammation sourced survival signals and the emergence of an immunosuppressive TME state. The ensuing tumor growth will further increase genomic instability leading to an accumulation of oncogenic alterations and consequently an increased dysregulation of cellular processes. The model structure assumed to be underlying these stochastic dynamics of cancer may suggest the existence of vulnerabilities that can be leveraged in the design of cancer therapies as well as points to potentially ineffective targets of therapeutic interventions (see Fig. 6). In particular,

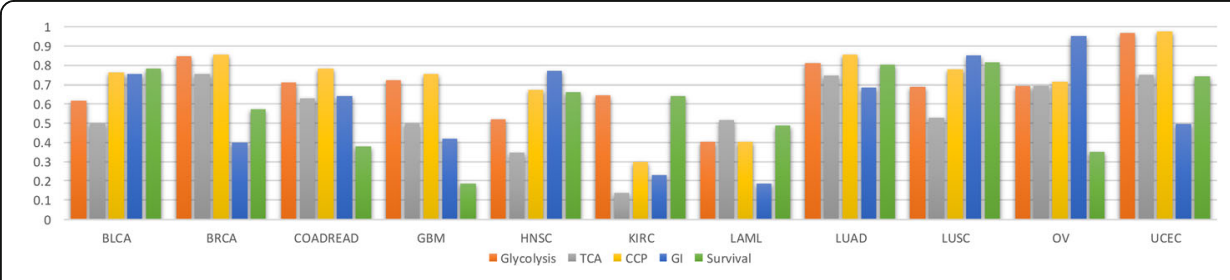

Fig. 5 Dysregulation probabilities for glycolysis, the TCA cycle, genome integrity, survival and the cell cycle progression through the restriction point 


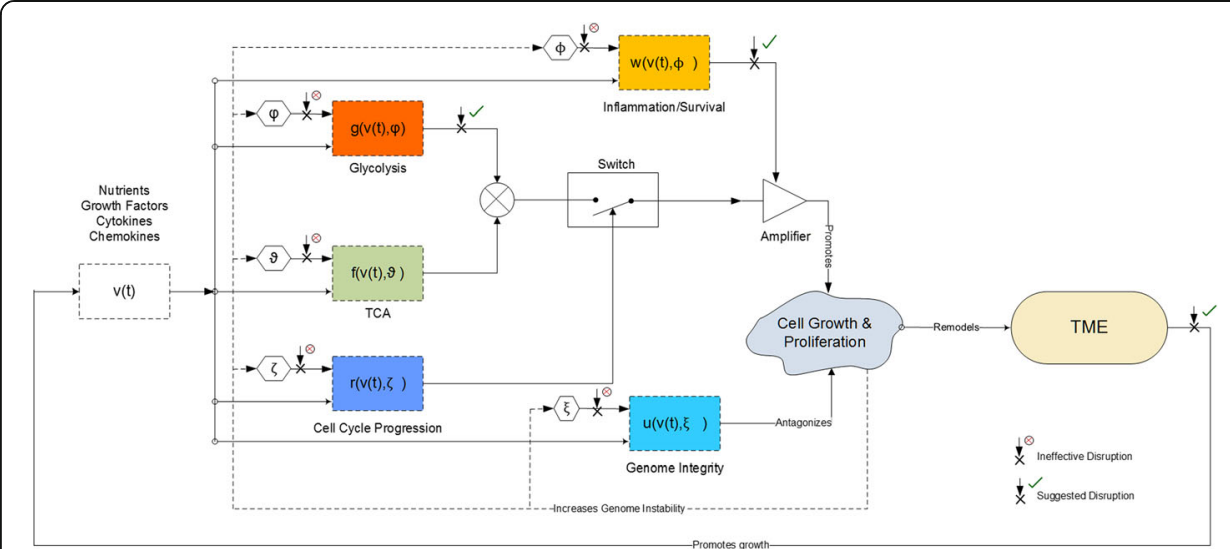

Fig. 6 Cancer as a stochastic system. Cancer is postulated to be initiated by the genetic-driven dysregulation of metabolism which is permitted to drive growth and proliferation due to the abrogation of the cell cycle restriction checkpoint and the inflammatory, survival and nutritional feedback of the TME. Therapeutic disruptions of the effectors of cancer growth dynamics are noted and qualified as potentially effective or ineffective based on the level and bandwidth of sensitivity to genomic instability

inhibitions of signaling pathways upstream of the metabolic processes may not be effective because of the potential onset of resistance due to the changing landscape of oncogenic mutations caused by genomic instability. In contrast, therapeutic effectiveness may be achievable by modulating the concentrations of lactate, growth factors and cytokines in the tumor microenvironment (see Fig. 6). Since these concentrations result from CCsTME dynamics driven by the integration of multiple regulatory signals from the cell and the extracellular environment, they embody, as a result, a smoothed out effect of genetic instability making them more tractable therapeutic targets as will be explored in the next section. However, the metabolic similarity between cancerous tumors and non-cancerous tissues of the muscles and of the nervous system, with respect to the upregulation of glycolysis and the shuttling of lactate, present a toxicity challenge for the clinical success of drugs targeting cancer metabolism, including those aimed at modulating the concentration of lactate in the TME $[72,73]$. The availability of comprehensive clinical data sets from the ongoing and planned clinical trials of metabolic inhibitors [72, 74], such as those targeting MCT1, LDHA, and GLUT1, will ultimately enable the clinical assessment of the therapeutic potential of targeting cancer metabolism as proposed in this perspective.

\section{Is there a cancer kill switch?}

Genetic alterations of cellular processes drive the inception of the CCs-CAFs-TAMs interaction system. This induces a progressive ratcheting up of the tumor proliferation dynamics leading to an ever growing genetic heterogeneity and an accumulation of genetic aberrations. The stable persistence of the CCs-TME dynamics enlisting the active involvement of the stroma and inflammatory cells towards cancer growth and proliferation will ultimately lead to invasion and metastasis. Many therapeutic approaches have been explored to target the causal elements believed to be maintaining the CCs-TMEs dynamics. These include the reduction of inflammation, the reduction of lactose excretion by cancer cells and the inhibition of TGF- $\beta$ ligands [62, 75-82]. In addition, most of the genes and pathways implicated in carcinogenesis have been considered for targeted therapies, including HER/EGFR [83, 84], PI3K-AKT-MTOR 
[85-87], RAS-RAF-ERK [88, 89], TGF- $\beta$ [76, 90], AMPK [91-94], the RB pathway [95-97], LDHA [75, 81, 98, 99], MCT1 [100, 101], and NF- Х $\beta / \mathrm{IKK}[59,77,102]$. While the prospect of targeted therapies may be promising [103-110], the specter of acquired disease resistance looms large, representing a persistent challenge to the development of a decisive cancer therapeutic strategy [111-116]. Nevertheless, we speculate that therapies targeting cancer metabolism and TME inflammation might prove effective if combined within a metronomic strategy with the aim to induce a progressive dragging of the CCs-TME dynamics away from tumor promotion and along a staged restoration of tissue homeostasis that avoids the incitement of drug resistance or radical wound repair-like tissue reactions. In particular, given the putative structure underlying the stochastic dynamics of cancer (Fig. 6), and the expected stochastic convergence of dysregulated cellular processes highlighted in Fig. 4, cancer cells must be first denied the glutamine and growth factors lifeline believed to be extended by the stroma in exchange for their secretion of lactate. This could be achieved through the inhibition of LDHA, suggested to be a promising cancer therapeutic target due its role as the catalyst of the pyruvate conversion into lactate, which is subsequently released in the TME [117-120]. Furthermore, reducing the concentration of lactate in the TME would limit cancer cells' inward uptake of lactate through MCT-1, which was suggested to indirectly increase glutaminolysis by upregulating the expression of the glutamine transporter ASCT2 in a MYC and HIF- $2 \alpha$ dependent manner [80]. In addition, a reduction of TME lactate, accepted to be a promoter of inflammation and angiogenesis [75], would not only weakens the TME sourced survival signals driving cancer growth, but it will also disrupt the CCs-CAFs interaction dynamics that are believed to enable a steady supply of recycled nutrients and growth factors from the stroma to the tumor [37]. In fact, we speculate that the lactate-promoted CCs-CAFs interactions and the suggested resulting supply of amino acids to cancer cells by CAFs undergoing autophagy [37], may be among the key inducers of carcinogenic transformations. Indeed, these CCs-CAFs interactions may be the drivers of the concurrent activation of AMPK and MTOR, which was recently reported to be inducible in an amino acid dependent manner [36]. In this respect, targeting the enzymes and metabolic transporters, such as LDHA, MCT1 and GLUT, to limit the production of lactate and its bi-directional shuttling between cancer cells and the TME would not only hinder the reprogramming of metabolism toward unchecked growth but it would also dampen inflammation and angiogenesis. However, targeting cancer metabolism is fraught with challenges associated with the genetic diversity of tumors, their metabolic flexibility and the dose limiting toxicity of metabolic inhibitors due to the fact that metabolic pathways in normal tissue are often equally upregulated just as in tumors [72]. Nevertheless, despite the genetic diversity of tumors and their tissue-specific metabolic reprogramming, the metabolic changes exhibited by different types of cancers are convergent towards an upregulated glycolysis and nucleotide synthesis, a downregulated fatty acid oxidation and a heterogeneous oxidation-phosphorylation [121, 122]. This may justify the exploration of therapies aimed at the metabolic vulnerabilities common across tumor types, in addition to the development of cancer-specific drugs targeting cancer metabolism. Towards this end, the tissue-specific metabolic transformations of tumor cells and their 
metabolic flexibility, which are due to the heterogeneous signaling and the dynamic distributions of nutrients, oxygen, and catabolites in the tumor microenvironment, need to be better understood and characterized to enable patient stratification based on the metabolic profiles of tumors and to target cancer metabolism accordingly. Overall, limiting the impact of metabolic dysregulation combined with a reduction of inflammation by targeting NF- $\chi \beta$ [77], TNF- $\alpha$ [123], the Jak/Stat pathway [124] and the TGF- $\beta$ pathway [76] has the potential of reestablishing tissue homeostasis and turning on as a result the immune cancer kill switch.

\section{Conclusions}

Cancer therapies should aim for a progressive disruption of the CCs-TME dynamics and target metabolic dysregulation and inflammation to partially restore tissue homeostasis and turn on the immune cancer kill switch. One potentially effective cancer therapeutic strategy is to induce the reduction of lactate and steer the TME to a state of reduced inflammation so as to enable an effective intervention of the immune system. The translation of this therapeutic approach into treatment regimens would however require more understanding of the adaptive complexity of cancer resulting from the interactions of cancer cells with the tumor microenvironment and the immune system.

\section{Additional file}

Additional file 1: Tables S1-S3. Estimated dysregulation probabilities of cellular processes, cardinal pathways and select genes by cancer type. (XLSX $28 \mathrm{~kb}$ )

Abbreviations

CAF: Cancer associated fibroblast; PPP: Pentose phosphate pathway; TAM: Tumor associated macrophages;

TCA: Tricarboxylic acid; TME: Tumor microenvironment

Acknowledgements

Not applicable.

Funding

Not applicable.

Availability of data and materials

Not applicable.

Ethics approval and consent to participate

Not applicable.

Consent for publication

Not applicable.

Competing interests

The author declares that he has no competing interests.

Publisher's Note

Springer Nature remains neutral with regard to jurisdictional claims in published maps and institutional affiliations.

Received: 14 May 2017 Accepted: 28 August 2017

Published online: 03 October 2017

References

1. Hanahan D, Weinberg RA. Hallmarks of cancer: the next generation. Cell. 2011;144(5):646-74

American Cancer Society. Cancer Facts \& Figures 2017. Atlanta: American Cancer Society; 2017.

3. Vu T, Sliwkowski MX, Claret FX. Personalized drug combinations to overcome trastuzumab resistance in HER2positive breast cancer. Biochim Biophys Acta. 2014;1846(2):353-65. 
4. Pentcheva-Hoang T, Simpson TR, Montalvo-Ortiz W, Allison JP. Cytotoxic T lymphocyte antigen-4 blockade enhances antitumor immunity by stimulating melanoma-specific T-cell motility. Cancer Immunol Res. 2014;2(10):970-80.

5. Fan X, Quezada SA, Sepulveda MA, Sharma P, Allison JP. Engagement of the ICOS pathway markedly enhances efficacy of CTLA-4 blockade in cancer immunotherapy. J Exp Med. 2014;211(4):715-25.

6. Pardoll DM. The blockade of immune checkpoints in cancer immunotherapy. Nat Rev Cancer. 2012;12(4):252-64.

7. Topalian SL, Atkins MB, Leming PD, Spigel DR, Antonia SJ, Horn L, Drake CG, Pardoll DM, Chen L, Sharfman WH, et al. Safety, activity, and immune correlates of anti-PD-1 antibody in cancer. N Engl J Med. 2012;366(26):2443.

8. Vivier E, Ugolini S, Blaise D, Chabannon C, Brossay L. Targeting natural killer cells and natural killer T cells in cancer. Nat Rev Immunol. 2012;12(4):239-52.

9. Scott AM, Wolchok JD, Old LJ. Antibody therapy of cancer. Nat Rev Cancer. 2012;12(4):278-87.

10. Wolchok JD, Berman DM, Lonberg N, Korman AJ, Hodi FS, Weber JS, Allison JP, Urba WJ, Robert C, O'Day SJ, et al. Development of ipilimumab: a novel immunotherapeutic approach for the treatment of advanced melanoma. Ann N Y Acad Sci. 2013;1291(1):1-13.

11. Amos SM, Duong CPM, Westwood JA, Ritchie DS, Junghans RP, Darcy PK, Kershaw MH. Autoimmunity associated with immunotherapy of cancer. Blood. 2011;118(3):499-509.

12. Themeli M, Kloss CC, Ciriello G, Fedorov VD, Perna F, Gonen M, Sadelain M. Generation of tumor-targeted human T lymphocytes from induced pluripotent stem cells for cancer therapy. Nat Biotechnol. 2013;31(10):928-33.

13. Stephan AG, Wright JF, Michael CM, Bruce LL, Carl HJ, Michael K, David B, Richard A, David LP, Susan RR, et al. Brief report: Chimeric antigen receptor-modified T cells for acute lymphoid leukemia. N Engl J Med. 2013;368(16):1509.

14. Robbins PF, Tycksen E, Samuels Y, Rosenberg SA, Lu Y-C, El-Gamil M, Li YF, Gross C, Gartner J, Lin JC, et al. Mining exomic sequencing data to identify mutated antigens recognized by adoptively transferred tumor-reactive $T$ cells. Nat Med. 2013;19(6):747-52.

15. Russell SJ, Peng K-W, Bell JC. Oncolytic virotherapy. Nat Biotechnol. 2012;30(7):658.

16. Wee S, Dhanak D, Li H, Armstrong SA, Copeland RA, Sims R, Baylin SB, Liu XS, Schweizer L. Targeting epigenetic regulators for cancer therapy. Ann N Y Acad Sci. 2014;1309:30-6.

17. Tsai H-C, Pappou E, Harris J, Yen R-WC, Ahuja N, Brock MV, Stearns V, Feller-Kopman D, Yarmus LB, Lin Y-C, et al. Transient low doses of DNA Demethylating agents exert durable anti-tumor effects on hematological and epithelial tumor cells. Cancer Cell. 2012;21(3):430-46.

18. Kim H-J, Bae S-C. Histone deacetylase inhibitors: molecular mechanisms of action and clinical trials as anti-cancer drugs. Am J Transl Res. 2011;3(2):166.

19. Al-Lazikani B, Banerji U, Workman P. Combinatorial drug therapy for cancer in the post-genomic era. Nat Biotechnol. 2012;30(7):679.

20. Bozic I, Le DT, Lipson EJ, Chapman PB, Diaz JLA, Vogelstein B, Nowak MA, Reiter JG, Allen B, Antal T, et al. Evolutionary dynamics of cancer in response to targeted combination therapy. elife. 2013;2(Journal Article):e00747.

21. Fedele C, Tothill RW, McArthur GA. Navigating the challenge of tumor heterogeneity in cancer therapy. Cancer Discov. 2014;4(2):146-8.

22. Derbal Y. On modeling of living organisms using hierarchical coarse-graining abstractions of knowledge. J Biol Syst. 2013;21:1350008.

23. Baum K, Politi AZ, Kofahl B, Steuer R, Wolf J. Feedback, mass conservation and reaction kinetics impact the robustness of cellular oscillations. PLoS Comput Biol. 2016;12(12):e1005298.

24. Denby CM, Im JH, Yu RC, Pesce CG, Brem RB. Negative feedback confers mutational robustness in yeast transcription factor regulation. Proc Natl Acad Sci U S A. 2012;109(10):3874-8.

25. Nurse P. Life, logic and information. Nature. 2008;454(7203):424-6.

26. Kitano H. Cancer robustness: tumour tactics. Nature. 2003;426(6963):125.

27. Kandoth C, McLellan MD, Vandin F, Ye K, Niu B, Lu C, Xie M, Zhang Q, McMichael JF, Wyczalkowski MA, et al. Mutational landscape and significance across 12 major cancer types. Nature. 2013;502(7471):333-9.

28. Ciriello G, Miller ML, Aksoy BA, Senbabaoglu Y, Schultz N, Sander C. Emerging landscape of oncogenic signatures across human cancers. Nat Genet. 2013;45(10):1127-33.

29. Tamborero D, Gonzalez-Perez A, Perez-Llamas C, Deu-Pons J, Kandoth C, Reimand J, Lawrence MS, Getz G, Bader GD, Ding $L$, et al. Comprehensive identification of mutational cancer driver genes across 12 tumor types. Sci Rep. 2013;3:2650.

30. Lawrence MS, Stojanov P, Mermel CH, Robinson JT, Garraway LA, Golub TR, Meyerson M, Gabriel SB, Lander ES, Getz G. Discovery and saturation analysis of cancer genes across 21 tumour types. Nature. 2014;505(7484):495-501.

31. Hoadley KA, Yau C, Wolf DM, Cherniack AD, Tamborero D, Ng S, Leiserson MD, Niu B, McLellan MD, Uzunangelov $\mathrm{V}$, et al. Multiplatform analysis of 12 cancer types reveals molecular classification within and across tissues of origin. Cell. 2014;158(4):929-44.

32. Zack TI, Schumacher SE, Carter SL, Cherniack AD, Saksena G, Tabak B, Lawrence MS, Zhsng CZ, Wala J, Mermel CH, et al. Pan-Cancer patterns of somatic copy number alteration. Nat Genet. 2013;45(10):1134-40.

33. Lorendeau D, Christen S, Rinaldi G, Fendt SM. Metabolic control of signalling pathways and metabolic autoregulation. Biol Cell. 2015;107(8):251-72.

34. Wellen KE, Thompson CB. A two-way street: reciprocal regulation of metabolism and signalling. Nat Rev Mol Cell Biol. 2012;13(4):270-6.

35. Ward PS, Thompson CB. Signaling in control of cell growth and metabolism. Cold Spring Harb Perspect Biol. 2012; 4(7):a006783.

36. Dalle Pezze P, Ruf S, Sonntag AG, Langelaar-Makkinje M, Hall P, Heberle AM, Razquin Navas P, van Eunen $K$, Tolle RC, Schwarz JJ, et al. A systems study reveals concurrent activation of AMPK and mTOR by amino acids. Nat Commun. 2016;7:13254.

37. Yuan Y, Jiang YC, Sun CK, Chen QM. Role of the tumor microenvironment in tumor progression and the clinical applications (review). Oncol Rep. 2016;35(5):2499-515.

38. Gandellini P, Andriani F, Merlino G, D'Aiuto F, Roz L, Callari M. Complexity in the tumour microenvironment: cancer associated fibroblast gene expression patterns identify both common and unique features of tumourstroma crosstalk across cancer types. Semin Cancer Biol. 2015;35:96-106. 
39. Son B, Lee $\mathrm{S}$, Youn H, Kim E, Kim W, Youn B. The role of tumor microenvironment in therapeutic resistance. Oncotarget. 2017:8(3):3933-45.

40. Swartz MA, lida N, Roberts EW, Sangaletti S, Wong MH, Yull FE, Coussens LM, DeClerck YA. Tumor microenvironment complexity: emerging roles in cancer therapy. Cancer Res. 2012;72(10):2473-80.

41. Anderson AR, Weaver AM, Cummings PT, Quaranta V. Tumor morphology and phenotypic evolution driven by selective pressure from the microenvironment. Cell. 2006;127(5):905-15.

42. Ko YH, Lin Z, Flomenberg N, Pestell RG, Howell A, Sotgia F, Lisanti MP, Martinez-Outschoorn UE. Glutamine fuels a vicious cycle of autophagy in the tumor stroma and oxidative mitochondrial metabolism in epithelial cancer cells: implications for preventing chemotherapy resistance. Cancer Biol Ther. 2011;12(12):1085-97.

43. Martinez-Outschoorn UE, Lin Z, Trimmer C, Flomenberg N, Wang C, Pavlides S, Pestell RG, Howell A, Sotgia F, Lisanti MP. Cancer cells metabolically "fertilize" the tumor microenvironment with hydrogen peroxide, driving the Warburg effect: implications for PET imaging of human tumors. Cell Cycle. 2011;10(15):2504-20.

44. Allavena P, Sica A, Solinas G, Porta C, Mantovani A. The inflammatory micro-environment in tumor progression: the role of tumor-associated macrophages. Crit Rev Oncol Hematol. 2008;66(1):1-9.

45. Komohara $Y$, Jinushi M, Takeya M. Clinical significance of macrophage heterogeneity in human malignant tumors. Cancer Sci. 2014;105(1):1-8

46. Fiaschi T, Marini A, Giannoni E, Taddei ML, Gandellini P, De Donatis A, Lanciotti M, Serni S, Cirri P, Chiarugi P. Reciprocal metabolic reprogramming through lactate shuttle coordinately influences tumor-stroma interplay. Cancer Res. 2012;72(19):5130-40.

47. Harper J, Sainson RC. Regulation of the anti-tumour immune response by cancer-associated fibroblasts. Semin Cancer Biol. 2014;25:69-77.

48. Popivanova BK, Kostadinova Fl, Furuichi K, Shamekh MM, Kondo T, Wada T, Egashira K, Mukaida N. Blockade of a chemokine, CCL2, reduces chronic colitis-associated carcinogenesis in mice. Cancer Res. 2009;69(19):7884-92.

49. Roca H, Varsos ZS, Sud S, Craig MJ, Ying C, Pienta KJ. CCL2 and interleukin-6 promote survival of human CD11b+ peripheral blood mononuclear cells and induce M2-type macrophage polarization. J Biol Chem. 2009;284(49):34342-54

50. Tommelein J, Verset L, Boterberg T, Demetter P, Bracke M, De Wever O. Cancer-associated fibroblasts connect metastasis-promoting communication in colorectal cancer. Front Oncol. 2015;5:63.

51. Laouar Y, Sutterwala FS, Gorelik L, Flavell RA. Transforming growth factor-beta controls $T$ helper type 1 cell development through regulation of natural killer cell interferon-gamma. Nat Immunol. 2005;6(6):600-7.

52. Kinoshita T, Ishii G, Hiraoka N, Hirayama S, Yamauchi C, Aokage K, Hishida T, Yoshida J, Nagai K, Ochiai A. Forkhead box P3 regulatory T cells coexisting with cancer associated fibroblasts are correlated with a poor outcome in lung adenocarcinoma. Cancer Sci. 2013;104(4):409-15.

53. Tamborero D, Gonzalez-Perez A, Perez-Llamas C, Deu-Pons J, Kandoth C, Reimand J, Lawrence MS, Getz G, Bader $G D$, Ding $L$, et al. Comprehensive identification of mutational cancer driver genes across 12 tumor types. Sci Rep. 2013:3(Journal Article):2650

54. Tuder RM, Lara AR, Thannickal VJ. Lactate, a novel trigger of transforming growth factor-beta activation in idiopathic pulmonary fibrosis. Am J Respir Crit Care Med. 2012;186(8):701-3.

55. Sumimoto H, Imabayashi F, Iwata T, Kawakami Y. The BRAF-MAPK signaling pathway is essential for cancerimmune evasion in human melanoma cells. J Exp Med. 2006;203(7):1651-6.

56. Shchors K, Shchors E, Rostker F, Lawlor ER, Brown-Swigart L, Evan Gl. The Myc-dependent angiogenic switch in tumors is mediated by interleukin 1beta. Genes Dev. 2006;20(18):2527-38.

57. Balkwill F. Cancer and the chemokine network. Nat Rev Cancer. 2004;4(7):540-50.

58. Lawrence T. The nuclear factor NF-kappaB pathway in inflammation. Cold Spring Harb Perspect Biol. 2009:1(6):a001651.

59. Tornatore L, Thotakura AK, Bennett J, Moretti M, Franzoso G. The nuclear factor kappa B signaling pathway: integrating metabolism with inflammation. Trends Cell Biol. 2012;22(11):557-66.

60. Yu H, Pardoll D, Jove R. STATs in cancer inflammation and immunity: a leading role for STAT3. Nat Rev Cancer. 2009:9(11):798-809.

61. Bromberg J, Wang TC. Inflammation and cancer: IL-6 and STAT3 complete the link. Cancer Cell. 2009;15(2):79-80.

62. Syed V. TGF-beta signaling in cancer. J Cell Biochem. 2016;117(6):1279-87.

63. Costanza B, Umelo IA, Bellier J, Castronovo V, Turtoi A. Stromal Modulators of TGF-beta in Cancer. J Clin Med. 2017:6(1). doi:10.3390/jcm6010007.

64. Zhang YE. Non-Smad pathways in TGF-beta signaling. Cell Res. 2009:19(1):128-39.

65. Huang JJ, Blobe GC. Dichotomous roles of TGF-beta in human cancer. Biochem Soc Trans. 2016;44(5):1441-54.

66. Seoane J, Gomis RR. TGF-beta Family Signaling in Tumor Suppression and Cancer Progression. Cold Spring Harb Perspect Biol; 2017. doi:10.1101/cshperspect.a022277.

67. Lebrun JJ. The dual role of TGFbeta in human cancer: from tumor suppression to cancer metastasis. ISRN Mol Biol. 2012;2012:381428

68. Flavell RA, Sanjabi S, Wrzesinski SH, Licona-Limon P. The polarization of immune cells in the tumour environment by TGFbeta. Nat Rev Immunol. 2010;10(8):554-67.

69. Adeegbe DO, Nishikawa H. Natural and induced T regulatory cells in cancer. Front Immunol. 2013:4:190.

70. Pickup M, Novitskiy S, Moses HL. The roles of TGFbeta in the tumour microenvironment. Nat Rev Cancer. 2013; 13(11):788-99

71. Courau T, Nehar-Belaid D, Florez L, Levacher B, Vazquez T, Brimaud F, Bellier B, Klatzmann D. TGF-beta and VEGF cooperatively control the immunotolerant tumor environment and the efficacy of cancer immunotherapies. JCl Insight. 2016;1(9):e85974.

72. Martinez-Outschoorn UE, Peiris-Pages M, Pestell RG, Sotgia F, Lisanti MP. Cancer metabolism: a therapeutic perspective. Nat Rev Clin Oncol. 2017;14(1):11-31.

73. Yamaguchi R, Perkins G. Challenges in targeting cancer metabolism for cancer therapy. EMBO Rep. 2012;13(12):1034-5.

74. Sabnis HS, Somasagara RR, Bunting KD. Targeting MYC Dependence by Metabolic Inhibitors in Cancer. Genes (Basel). 2017;8(4):114. doi:10.3390/genes8040114. 
75. Doherty JR, Cleveland JL. Targeting lactate metabolism for cancer therapeutics. J Clin Invest. 2013;123(9):3685-92.

76. Neuzillet C, Tijeras-Raballand A, Cohen R, Cros J, Faivre S, Raymond E, de Gramont A. Targeting the TGFbeta pathway for cancer therapy. Pharmacol Ther. 2015;147:22-31.

77. Erstad DJ, Cusack JC Jr. Targeting the NF-kappaB pathway in cancer therapy. Surg Oncol Clin N Am. 2013;22(4): 705-46.

78. Manerba M, Di lanni L, Govoni M, Roberti M, Recanatini M, Di Stefano G. Lactate dehydrogenase inhibitors can reverse inflammation induced changes in colon cancer cells. Eur J Pharm Sci. 2017;96:37-44.

79. Miao P, Sheng S, Sun X, Liu J, Huang G. Lactate dehydrogenase a in cancer: a promising target for diagnosis and therapy. IUBMB Life. 2013;65(11):904-10.

80. Perez-Escuredo J, Dadhich RK, Dhup S, Cacace A, Van Hee VF, De Saedeleer CJ, Sboarina M, Rodriguez F, Fontenille MJ, Brisson L, et al. Lactate promotes glutamine uptake and metabolism in oxidative cancer cells. Cell Cycle. 2016;15(1):72-83.

81. Rani R, Kumar V. Recent update on human lactate Dehydrogenase enzyme 5 (hLDH5) inhibitors: a promising approach for cancer chemotherapy. J Med Chem. 2016;59(2):487-96.

82. Todoric J, Antonucci L, Karin M. Targeting inflammation in cancer prevention and therapy. Cancer Prev Res (Phila) 2016:9(12):895-905.

83. Seshacharyulu P, Ponnusamy MP, Haridas D, Jain M, Ganti AK, Batra SK. Targeting the EGFR signaling pathway in cancer therapy. Expert Opin Ther Targets. 2012;16(1):15-31.

84. Klement GL, Goukassian D, Hlatky L, Carrozza J, Morgan JP, Yan X. Cancer therapy targeting the HER2-PI3K pathway: potential impact on the heart. Front Pharmacol. 2012;3:113.

85. Sadeghi N, Gerber DE. Targeting the PI3K pathway for cancer therapy. Future Med Chem. 2012;4(9):1153-69.

86. Fu Y, Zhang Y, Gao M, Quan L, Gui R, Liu J. Alisertib induces apoptosis and autophagy through targeting the AKT/ mTOR/AMPK/p38 pathway in leukemic cells. Mol Med Rep. 2016;14(1):394-8.

87. Bartholomeusz C, Gonzalez-Angulo AM. Targeting the PI3K signaling pathway in cancer therapy. Expert Opin Ther Targets. 2012;16(1):121-30.

88. Samatar AA, Poulikakos PI. Targeting RAS-ERK signalling in cancer: promises and challenges. Nat Rev Drug Discov. 2014;13(12):928-42.

89. Yu Z, Ye S, Hu G, Lv M, Tu Z, Zhou K, Li Q. The RAF-MEK-ERK pathway: targeting ERK to overcome obstacles to effective cancer therapy. Future Med Chem. 2015;7(3):269-89.

90. Smith AL, Robin TP, Ford HL. Molecular pathways: targeting the TGF-beta pathway for cancer therapy. Clin Cancer Res. 2012;18(17):4514-21.

91. Plews RL, Mohd Yusof A, Wang C, Saji M, Zhang X, Chen CS, Ringel MD, Phay JE. A novel dual AMPK activator/ mTOR inhibitor inhibits thyroid cancer cell growth. J Clin Endocrinol Metab. 2015;100(5):E748-56.

92. Wang Z, Liu P, Chen Q, Deng S, Liu X, Situ H, Zhong S, Hann S, Lin Y. Targeting AMPK signaling pathway to overcome drug resistance for cancer therapy. Curr Drug Targets. 2016;17(8):853-64.

93. Jia $\mathrm{Y}$, Wang $\mathrm{H}$, Wang $\mathrm{Q}$, Ding $\mathrm{H}$, Wu H, Pan $\mathrm{H}$. Silencing Nrf2 impairs glioma cell proliferation via AMPK-activated mTOR inhibition. Biochem Biophys Res Commun. 2016;469(3):665-71.

94. Daurio NA, Tuttle SW, Worth AJ, Song EY, Davis JM, Snyder NW, Blair IA, Koumenis C. AMPK activation and metabolic reprogramming by Tamoxifen through estrogen receptor-independent mechanisms suggests new uses for this therapeutic modality in cancer treatment. Cancer Res. 2016;76(11):3295-306.

95. Knudsen ES, Wang JY. Targeting the RB-pathway in cancer therapy. Clin Cancer Res. 2010;16(4):1094-9.

96. Radulescu RT, Fahraeus R. Targeting the RB pathway for cancer therapy: peptide mimetic foundations and promise. Am J Transl Res. 2010;2(2):209.

97. Spring L, Bardia A, Modi S. Targeting the cyclin D-cyclin-dependent kinase (CDK) 4/6-retinoblastoma pathway with selective CDK 4/6 inhibitors in hormone receptor-positive breast cancer: rationale, current status, and future directions. Discov Med. 2016;21(113):65-74

98. Ooi AT, Gomperts BN. Molecular pathways: targeting cellular energy metabolism in cancer via inhibition of SLC2A1 and LDHA. Clin Cancer Res. 2015;21(11):2440-4.

99. Boudreau A, Purkey HE, Hitz A, Robarge K, Peterson D, Labadie S, Kwong M, Hong R, Gao M, Del Nagro C, et al. Metabolic plasticity underpins innate and acquired resistance to LDHA inhibition. Nat Chem Biol. 2016;12(10):779-86.

100. Doherty JR, Yang C, Scott KE, Cameron MD, Fallahi M, Li W, Hall MA, Amelio AL, Mishra JK, Li F, et al. Blocking lactate export by inhibiting the Myc target MCT1 disables glycolysis and glutathione synthesis. Cancer Res. 2014;74(3):908-20.

101. Fang J, Quinones QJ, Holman TL, Morowitz MJ, Wang Q, Zhao H, Sivo F, Maris JM, Wahl ML. The H+-linked monocarboxylate transporter (MCT1/SLC16A1): a potential therapeutic target for high-risk neuroblastoma. Mol Pharmacol. 2006;70(6):2108-15.

102. Pozdeyev N, Berlinberg A, Zhou Q, Wuensch K, Shibata H, Wood WM, Haugen BR. Targeting the NF-kappaB pathway as a combination therapy for advanced thyroid cancer. PLoS One. 2015;10(8):e0134901.

103. Ribas A, Tumeh PC. The future of cancer therapy: selecting patients likely to respond to PD1/L1 blockade. Clin Cancer Res. 2014;20(19):4982-4.

104. Koutras AK, Starakis I, Kyriakopoulou U, Katsaounis P, Nikolakopoulos A, Kalofonos HP. Targeted therapy in colorectal cancer: current status and future challenges. Curr Med Chem. 2011;18(11):1599-612.

105. Chan BA, Hughes BG. Targeted therapy for non-small cell lung cancer: current standards and the promise of the future. Transl Lung Cancer Res. 2015:4(1):36-54

106. Aggarwal C. Targeted therapy for lung cancer: present and future. Ann Palliat Med. 2014;3(3):229-35.

107. Yuan DD, Zhu ZX, Zhang X, Liu J. Targeted therapy for gastric cancer: current status and future directions (review). Oncol Rep. 2016;35(3):1245-54.

108. Kanat O, O'Neil B, Shahda S. Targeted therapy for advanced gastric cancer: a review of current status and future prospects. World J Gastrointest Oncol. 2015;7(12):401-10.

109. Thanapprapasr D, Cheewakriangkrai $C$, Likittanasombut $P$, Thanapprapasr K, Mutch DG. Targeted endometrial cancer therapy as a future prospect. Womens Health (Lond). 2013;9(2):189-99. 
110. Telli ML, Sledge GW. The future of breast cancer systemic therapy: the next 10 years. J Mol Med (Berl). 2015;93(2):119-25.

111. Nonnenmacher L, Hasslacher S, Zimmermann J, Karpel-Massler G, La Ferla-Bruhl K, Barry SE, Burster T, Siegelin MD, Bruhl O, Halatsch ME, et al. Cell death induction in cancer therapy - past, present, and future. Crit Rev Oncog. 2016;21(3-4):253-67.

112. Ray K. Cancer: therapy for colorectal cancer liver metastases: understanding resistance. Nat Rev Gastroenterol Hepatol. 2016;13(12):681.

113. Check Hayden E. Cancer complexity slows quest for cure. Nature. 2008:455(7210):148.

114. Montoni A, Robu M, Pouliot E, Shah GM. Resistance to PARP-inhibitors in cancer therapy. Front Pharmacol. 2013;4:18

115. Kam Y, Das T, Tian H, Foroutan P, Ruiz E, Martinez G, Minton S, Gillies RJ, Gatenby RA. Sweat but no gain: inhibiting proliferation of multidrug resistant cancer cells with "ersatzdroges". Int J Cancer. 2015;136(4):E188-96.

116. Sun Y. Tumor microenvironment and cancer therapy resistance. Cancer Lett. 2016;380(1):205-15.

117. Fiume L, Manerba M, Vettraino M, Di Stefano G. Impairment of aerobic glycolysis by inhibitors of lactic dehydrogenase hinders the growth of human hepatocellular carcinoma cell lines. Pharmacology. 2010;86(3):157-62.

118. Zhai X, Yang Y, Wan J, Zhu R, Wu Y. Inhibition of LDH-A by oxamate induces G2/M arrest, apoptosis and increases radiosensitivity in nasopharyngeal carcinoma cells. Oncol Rep. 2013;30(6):2983-91.

119. Liu X, Yang Z, Chen Z, Chen R, Zhao D, Zhou Y, Qiao L. Effects of the suppression of lactate dehydrogenase a on the growth and invasion of human gastric cancer cells. Oncol Rep. 2015;33(1):157-62.

120. Le A, Cooper CR, Gouw AM, Dinavahi R, Maitra A, Deck LM, Royer RE, Vander Jagt DL, Semenza GL, Dang CV. Inhibition of lactate dehydrogenase a induces oxidative stress and inhibits tumor progression. Proc Natl Acad Sci U S A. 2010;107(5):2037-42.

121. Hu J, Locasale JW, Bielas JH, O'Sullivan J, Sheahan K, Cantley LC, Vander Heiden MG, Vitkup D. Heterogeneity of tumor-induced gene expression changes in the human metabolic network. Nat Biotechnol. 2013;31(6):522-9.

122. Gaude E, Frezza C. Tissue-specific and convergent metabolic transformation of cancer correlates with metastatic potential and patient survival. Nat Commun. 2016;7:13041.

123. Baniyash M, Sade-Feldman M, Kanterman J. Chronic inflammation and cancer: suppressing the suppressors. Cancer Immunol Immunother. 2014;63(1):11-20.

124. Roxburgh CS, McMillan DC. Therapeutics targeting innate immune/inflammatory responses through the interleukin-6/JAK/STAT signal transduction pathway in patients with cancer. Transl Res. 2016;167(1):61-6.

\section{Submit your next manuscript to BioMed Central and we will help you at every step:}

- We accept pre-submission inquiries

- Our selector tool helps you to find the most relevant journal

- We provide round the clock customer support

- Convenient online submission

- Thorough peer review

- Inclusion in PubMed and all major indexing services

- Maximum visibility for your research

Submit your manuscript at www.biomedcentral.com/submit 